\section{(6) OPEN ACCESS}

\begin{abstract}
- Additional material is published online. To view this file please visit the journal (http://dx.doi.org/10.1136/ tobaccocontrol-2013-051364)

${ }^{1}$ Department of Health, Behavior and Society, Johns Hopkins Bloomberg School of Public Health, Baltimore, Maryland, USA

${ }^{2}$ Department of Environmental Health Sciences, Johns Hopkins Bloomberg School of Public Health, Baltimore, Maryland, USA
\end{abstract}

\section{Correspondence to} Dr Frances A Stillman, Johns Hopkins Bloomberg School of Public Health, 2213 McElderry Street, 4th Floor, Baltimore, MD 21205, USA:

fstillma@jhsph.edu

Received 25 September 2013 Accepted 19 February 2014 Published Online First 17 March 2014

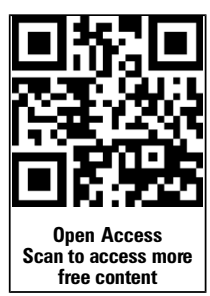

CrossMark

To cite: Stillman $\mathrm{FA}$ Soong A, Kleb C, et al. Tob Control 2015;24:528-531.

\title{
A review of smoking policies in airports around the world
}

\author{
Frances A Stillman, ${ }^{1}$ Andrea Soong, ${ }^{1}$ Cerise Kleb, ${ }^{1}$ Ashley Grant, ${ }^{1}$ Ana Navas-Acien ${ }^{2}$
}

\begin{abstract}
Objective To review smoking policies of major international airports, to compare these policies with corresponding incountry tobacco control legislation and to identify areas of improvement for advancing smokefree policy in airports.
\end{abstract}

Methods We reviewed smoking policies of 34 major international airports in five world regions, and collected data on current national and subnational legislation on smoke-free indoor places in the corresponding airport locations. We then compared airport smoking policies with local legislation. Additionally, we collected anecdotal information concerning smoking rules and practices in specific airports from an online traveller website.

Results We found that $52.9 \%$ of the airports reviewed had indoor smoking rooms or smoking areas; smoking policy was unknown or unstated for two airports. 55.9\% of the airports were located in countries where national legislation allowed designated smoking rooms and areas, while $35.3 \%$ were in smoke-free countries. Subnational legislation restricted smoking in $60 \%$ of the airport locations, while $40 \%$ were smoke-free. $71.4 \%$ of the airport locations had subnational legislation that allowed smoke-free laws to be more stringent than at the national level, but only half of these places had enacted such laws.

Conclusions Despite the increasing presence of smoke-free places and legal capacity to enact stricter legislation at the local level, airports represent a public and occupational space that is often overlooked in national or subnational smoke-free policies. Secondhand smoke exposure in airports can be reduced among travellers and workers by implementing and enforcing smoke-free policies in airports. Additionally, existing information on smoke-free legislation lacks consistent terminology and definitions, which are needed to inform future tobacco control policy within airports and in the law.

\section{INTRODUCTION}

Global tobacco control has been strengthened in recent decades through efforts to prevent tobacco consumption and secondhand smoke (SHS) exposure among smokers and non-smokers. ${ }^{1}$ An increasing number of countries have made all indoor public places smoke-free. However, designated smoking rooms (DSRs), lounges and other indoor smoking areas still exist in major airports. Although smoking is banned on domestic and international flights in most countries and airlines, concerns over SHS exposure in airports remain. A recent US study added to existing evidence that travellers and workers are at risk for SHS exposure from indoor smoking areas in airports. $^{2}$
The purpose of this study was to compare the smoking policies of major international airports across the world with corresponding incountry legislation of smoke-free indoor public places. We also examine anecdotal information from travellers about airport rooms and areas where smoking is officially or unofficially allowed. The findings from this study highlight discrepancies between smoke-free legislation and airport practices, and this information could be useful for improving smoke-free policies or legislation. Prior research on the health effects of SHS, including the adverse effects experienced specifically by airline employees, is well documented. ${ }^{3}{ }^{4}$ Research on SHS in airport smoking areas, while extensive, has focused exclusively on US based airports. ${ }^{56}$

\section{METHODS \\ Sample}

Data was collected from 34 major airports selected from five world regions: Africa, Asia, Europe, the Western Pacific and the Americas. To identify airports, we performed an online search using the terms 'largest, busiest or major airports'. Within each region, we used passenger traffic as the selection criterion for identifying major airports. The most recent statistics on annual passenger traffic for each airport came from the Airports Council International data repository, ${ }^{7}$ and from individual airport and government aviation authority websites. Airports Council International traffic data was from 2011, while data from airport and aviation websites ranged from 2010 to 2012. Some of the airports in certain regions were comparatively small on the international scale, such as those in Africa, but had the highest passenger traffic in the immediate country or region. This selection process ensured a diversity of countries and broader representation than selecting airports with the highest passenger traffic overall.

\section{Measures}

Airport data

We searched individual airport websites for information on airport smoking policy in July 2012, and checked for updates in July 2013. We looked for either an explicit statement of indoor smoking policy, or for listings of DSRs and other smoking areas. Smoking areas were defined as any open or enclosed indoor place where smoking was permitted within the airport, including rooms, restaurants, bars and business lounges. Policies were categorised as 'smoke-free' when smoking was prohibited in all indoor areas, 'smoking restricted' when DSRs and other smoking areas existed, and 'not restricted' when there were no rules on indoor smoking. We did not expect any airports to have a 'not restricted' policy. 
Local data

We searched data on legislation of smoke-free public places for each airport location. We consulted three sources for this data. The Global Smokefree Partnership (GSP) was selected as the primary source because it had the most complete information on all countries in our analysis, with the most systematic categorisation of smoke-free legislation status as of $2013 .{ }^{8}$ We adapted the GSP smoke-free definition to encompass the same three categories we used for airport smoking policy: 'Smoke-free' legislation was defined as all public places completely smoke-free, or at least $90 \%$ of the country's population covered by complete subnational smoke-free legislation. 'Smoking restricted' legislation was defined as allowing smoking in at least one type of public place (eg, public transportation), or allowing smoking rooms or other exemptions (eg, hotels) in otherwise smoke-free places. 'Not restricted' legislation was defined as having no public places completely smoke-free.

Data on smoke-free legislation collected from GSP was crosschecked for consistency with data from the WHO tobacco control country profiles. ${ }^{9}$ If local data was not available from GSP or WHO Report on the Global Tobacco Epidemic, ${ }^{9}$ we searched the Campaign for Tobacco Free Kids (CTFK) website as a tertiary source. ${ }^{10}$ If legislative information was not available from any of the three sources, the data was categorised as 'Unreported.' It should be noted that subnational local data from CTFK was presented differently from GSP and WHO, and could not feasibly be categorised into smoke-free, smoking restricted or not restricted. Instead we recorded CTFK subnational level data in a series of three yes/no criteria, similarly to how it appears on the website: whether subnational jurisdictions at large were permitted to enact smoke-free law; if yes, whether such law could be more stringent than national law; if yes whether at least one jurisdiction had smoke-free laws that were more stringent than national law.

\section{Comparison of airport and local data}

Airport data were compared with local data to examine whether airport smoking policies were consistent with current legislation on smoking in indoor public places. Airport policy was compared with national and subnational level data. We counted an inconsistency if an airport had a lower level of smoking policy compared with local legislation (eg, a smoking restricted airport in a smoke-free country, city or state). Using the subnational legislation data from CTFK, we also evaluated how many airport locations could potentially enact stricter smoke-free laws, and whether or not this had been achieved.

\section{Anecdotal traveller data}

We collected anecdotal information from a website named Smoking in Transit, ${ }^{11}$ an online site targeted at smokers where users can search for airport smoking areas and comment on their experiences and observations of smoking rules. Several similar sites exist that provide similar anecdotal information from smokers on smoking in airports, but Smoking in Transit had the largest collection of reports on airports across the world. We reviewed comments that were posted between 2011 and 2013, which we accessed in July 2012 and July 2013. As of September 2013, the site was down and unavailable for access.

\section{RESULTS \\ Sample}

We reviewed 34 airports from five regions: Africa (4), Asia (9), Europe (6), the Western Pacific (3) and the Americas (12) (see online supplementary table S1). Total annual passenger traffic ranged from 8434799 in Cape Town International in South Africa to 92389023 in Hartsfield Jackson Atlanta International in the USA.

\section{Airport data}

For airport policies, $14(41.2 \%)$ were stated as smoke-free, 18 $(52.9 \%)$ were smoking restricted and two were unreported (Mohammed V International, Morocco and Soekarno-Hatta International, Indonesia). Smoke-free airports were located in Asia (1), Europe (2), Western Pacific (3) and the Americas (8).

\section{Local data}

Data on legislation at the national level was reported for all 34 airport locations. National level legislation of smoking in indoor public places was smoke-free in $12(35.3 \%)$ airport locations, smoking restricted in 19 (55.9\%) locations and not restricted in three locations (8.8\%). National level smoke-free legislation existed in airports located in Asia (1), Europe (3), the Western Pacific (3) and the Americas (5). Smoking was not restricted at the national level in three airports located in Asia: two in China (Beijing Capital International and Hong Kong International) and one in Japan (Tokyo International).

Subnational level data from at least one source was reported for 29 airport locations in total. According to data from the first two sources (reported in 20 locations), subnational legislation was reported as smoke-free in eight (40.0\%) locations, smoking restricted in $12(60.0 \%)$. According to data from the third source (reported in 21 locations), 16 airports (76.2\%) were in locations that permitted subnational jurisdictions to have smokefree law, while 5 were not permitted (23.8\%). Among locations that permitted subnational smoke-free law, 15 (71.4\%) allowed smoke-free law to be more stringent than national law, and 11 $(52.4 \%)$ were known to have at least one subnational jurisdiction with more stringent smoke-free law than national law.

\section{Comparison of airport and local data}

The two airports with no stated smoking policy (Mohammed V, Morocco and Soekarno-Hatta, Indonesia) were dropped from this portion of the analysis $(n=32)$. At the national level, airport smoking policy was inconsistent with legislation in three cases (9.4\%): Ataturk International, Turkey; El Dorado, Colombia; and Suvarnabhumi, Thailand. At the subnational level, airport smoking policy was inconsistent with legislation in two cases $(10.0 \%, \mathrm{n}=20)$ : Ataturk International and Mexico City International.

\section{Anecdotal traveller data}

Smoking areas mentioned in the qualitative traveller reports included DSRs, business lounges, pubs/bars and eateries. Specific directions to find these areas were noted in 13 (38.2\%) airports.

\section{DISCUSSION}

Our review found that the majority of major international airports evaluated contained DSRs or other indoor smoking areas, and several of these airports were located in countries with smoke-free status. Ataturk International is an example, as it allowed smoking in lounges despite national and subnational smoke-free legislation. South Africa, which had two airports in the review, presents a situation in which the country may be able to enact stricter subnational smoking bans in airports, but has not done this. These findings highlight gaps in current tobacco control legislation. Interestingly, a number of the 
airports with indoor smoking areas in our review were praised as some of the top performing airports in the world, such as Singapore Changi. ${ }^{12}$ There were some positive implications in the data as well: Madrid Barajas Airport allowed DSRs despite a 2006 ban on smoking in enclosed workplaces, ${ }^{13}$ but we learned that this airport has since enacted a smoke-free policy in line with their current national legislation.

We collected airport policy data as it was reported on websites several times throughout this review, but it is possible that policies have changed in the meantime. Extensive searching was often required to find information on airport smoking policy, if it was available, thus it is likely that consumers would have similar issues. Airports should state their smoking policy explicitly on their websites, and have easily accessible and visible links to the information. Information on airport DSRs and other smoking areas was easier to find from traveller reports on the Smoking in Transit website, but this was a biased source of information targeted at smokers. However, the anecdotal data from Smoking in Transit provided insight into compliance or enforcement of airport smoking policy: three of the airports that supposedly prohibited all indoor smoking were mentioned as having areas where smoking was in fact permitted. One report said of Indonesia's Soekarno-Hatta airport: 'Terminal 1 Domestic: Smoking is not allowed but the law is not enforced and everybody is smoking.' Several traveller reports gave explicit directions to finding a DSR or smoking area, or named specific bars and airline lounges where smoking was allowed.

A consistent definition of smoke-free and method for assessing smoke-free status is needed in order to advance knowledge sharing between policy makers and tobacco control organisations. We used multiple sources to capture a wide range of data on smoking policy, but the limitation in doing this was that each source had its own definition of smoke-free status, which sometimes conflicted with the other sources. Subnational level data was also unreported for a number of locations, which reduced our analytical sample for the comparison between airport policy and local legislation. Close examination of the legislative structure in each country would reveal which airports are publicly or privately managed, and whether they actually have the power to enact DSR bans, as this could have confounded our results. Airports with unreported local data, such as Morocco, would benefit from more in-depth examination of smoke-free laws and specific provisions in the law to determine their smoke-free status as a country. Future studies on the topic could also include observational data collected on site at airports to assess current smoking policy compliance or enforcement, rather than relying solely on data from internet resources that are often out of date or largely biased.

Research consistently shows that smoking rooms do not effectively protect outer areas from SHS exposure due to leakage of smoking air in the room. ${ }^{2}{ }^{14-16}$ This is especially concerning for people who may be obligated to spend time near smoking areas, for example custodial staff or children of smokers. Moreover, the tobacco industry has influenced the design, construction and promotion of smoking rooms in airports in the past. $^{13} 17$ We recommend that newly proposed state, local or national smoke-free legislation-or revisions being made to existing smoke-free law-should explicitly include airports as part of indoor workplace smoking bans. Indeed, the existing information on smoke-free law appears to consider airports solely as a place of mass transit rather than a workplace.

Airports themselves should also be encouraged to adopt internal policies to protect all persons who work or use the airport facilities. Because the process of changing state or national law takes time and differs by country, it is recommended in the short term for airports to provide reliable, easily accessible information to patrons regarding the airport smoking policy. With this standard, consumers can make informed decisions to avoid certain areas, lounges or restaurants in the airport to avoid SHS exposure. However, airline and airport employees may not always have a choice in avoiding these areas. The health of all travellers and workers should be held to higher standards by airports and governments by eliminating and prohibiting DSRs and other smoking areas in airports, ${ }^{13}$ and adopting completely smoke-free policies should implement and enforce completely smoke-free airports.

\section{What this paper adds}

- Currently, information concerning airport smoking policy is not located in one site and has not been reported in a consistent manner except for the largest airports in the USA.

- Nearly $59 \%$ of airports included in the review had designated smoking rooms.

- Despite the increasing presence of smoke-free places and legal capacity to enact stricter legislation at the local level, airports represent a public and occupational space that is often overlooked in national or subnational smoke-free policies.

Contributors FAS developed the idea for this article. The policy data and relevant literature review was conducted by CK, AG and AS. The article was written by AS, FAS and AG. Presubmission review and editing was completed by FAS, AS and AN-A. The guarantor is FAS.

Funding The work was supported by grant number 108594 from the Flight Attendant Medical Research Institute (FAMRI) to the Johns Hopkins FAMRI Center of Excellence. The funder had no role in the study design, collection, analysis or interpretation of data, writing of the report, nor in the decision to submit the paper for publication.

\section{Competing interests None.}

Provenance and peer review Not commissioned; externally peer reviewed.

Data sharing statement We are willing to make all data available to any interested parties.

Open Access This is an Open Access article distributed in accordance with the Creative Commons Attribution Non Commercial (CC BY-NC 3.0) license, which permits others to distribute, remix, adapt, build upon this work non-commercially, and license their derivative works on different terms, provided the original work is properly cited and the use is non-commercial. See: http://creativecommons.org/ licenses/by-nc/3.0/

\section{REFERENCES}

1 Levy DT, Ellis JA, May D, et al. Smoking-related deaths averted due to three years of policy progress. Bull World Health Organ 2013;91:509-18.

2 King B, Tynan M, Promoff G, et al. Indoor air quality at nine large-hub airports with and without designated smoking areas-United States, October-November 2012. MMWR Morb Mortal Wkly Rep 2012;61:948-51. http://www.cdc.gov/mmwr/ preview/mmwrhtml/mm6146a4.htm?s_cid=mm6146a4_e

3 Beatty AL, Haight TJ, Redberg RF. Associations between respiratory illnesses and secondhand smoke exposure in flight attendants: a cross-sectional analysis of the Flight Attendant Medical Research Institute Survey. Environ Health 2011; $10: 81$.

4 U.S. Department of Health and Human Services. The health consequences of involuntary exposure to tobacco smoke: a report of the surgeon general. Atlanta, GA: U.S. Department of Health and Human Services, Centers for Disease Control and Prevention, Coordinating Center for Health Promotion, National Center for Chronic Disease Prevention and Health Promotion, Office on Smoking and Health, 2006. 
5 Americans for Nonsmokers' Rights Foundation [Internet]. Smoking Policies in the 35 Busiest U.S. Airports. [Updated July 2013; cited July 2013]. http://www.no-smoke. org/pdf/smokingpoliciesbusiestairports.pdf

6 Centers for Disease Control and Prevention, Morbidity and Mortality Weekly Report. Smoking restrictions in large-hub airports-United States, 2002 and 2010. MMWR 2010:59:1484-7.

7 Airports Council International [Internet]. Passenger Traffic 2011 FINAL. [Updated July 2013; cited August 2013]. http://www.aci.aero/Data-Centre/Annual-Traffic-Data/ Passengers/2011-final

8 Global Smokefree Partnership [Internet]. Global map of smokefree laws -2013. [Updated 2013; cited July 2013]. http://www.globalsmokefreepartnership.org/ global-map-of-smokefree-laws-2013/

9 World Health Organization [Internet]. WHO|Tobacco control country profiles. [Updated 2013; cited January 2014]. http://www.who.int/tobacco/surveillance/ policy/country_profile/en/index.html

10 Campaign for Tobacco Free Kids [Internet]. Legislation-Tobacco Control Laws. [Updated January 2014; cited January 2014]. http://www.tobaccocontrollaws.org/ legislation
11 Smoking in Transit [Internet]. Smoking area search engine. [Updated July 2013; cited July 2012 and July 2013]. http://www.smokingtransit.com/search-airportsmoking-areas.html

12 Airports Council International [Media release]. Airport service quality award winner and director general's roll of excellence inductees honoured at gala dinner. June 2013. http:/l www.aci.aero/News/Releases/Most-Recent/2013/06/11/Airport-Service-Quality-AwardWinners-and-Director-Generals-Roll-of-Excellence-Inductees-Honoured-at-Gala-Dinner

13 Fernandez E. Spain: partial airport bans unacceptable. Tob Control 2008;17:147-50.

14 Lee $\mathrm{K}$, Hahn EJ, Robertson $\mathrm{HE}$, et al. Air quality in and around airport enclosed smoking rooms. Nicotine Tob Res 2010;12:665-8.

15 Wagner J, Sullivan DP, Faulkner D, et al. Environmental tobacco smoke leakage from smoking rooms. J Occup Environ Hyg 2004;1:110-8.

16 Pion M, Givel MS. Airport smoking rooms don't work. Tob Control 2004;13: i37-40.

17 Americans for Nonsmokers' Rights Foundation [Internet]. Smoking in Airports: Selected Tobacco Industry Documents. Sept 2001 [cited July 2013]. http://www. no-smoke.org/document.php?id=246 